\title{
THE GOODNESS OF LONG PATH WITH RESPECT TO MULTIPLE COPIES OF COMPLETE GRAPHS
}

\author{
I WAYAN SUDARSANA
}

Combinatorial and Applied Mathematics Research Group (CAMRG)

Department of Mathematics, Faculty of Mathematics and Natural Sciences Tadulako University, Jalan Soekarno-Hatta Km. 8 Palu 94118 Indonesia sudarsanaiwayan@yahoo.co.id

\begin{abstract}
Let $H$ be a graph with the chromatic number $\chi(H)$ and the chromatic surplus $s(H)$. A connected graph $G$ of order $n$ is called good with respect to $H$, $H$-good, if $R(G, H)=(n-1)(\chi(H)-1)+s(H)$. The notation $t K_{m}$ represents a graph with $t$ identical copies of complete graphs on $m$ vertices, $K_{m}$. In this note, we discuss the goodness of path $P_{n}$ with respect to $t K_{m}$. It is obtained that the path $P_{n}$ is $t K_{m}$-good for $m, t \geq 2$ and sufficiently large $n$. Furthermore, it is also obtained the Ramsey number $R\left(G, t K_{m}\right)$, where $G$ is a disjoint union of paths.

Key words and Phrases: $(G, H)$-free, $H$-good, complete graph, path, Ramsey number.
\end{abstract}

\begin{abstract}
Abstrak. Notasi $H$ menyatakan graf dengan bilangan kromatik $\chi(H)$ dan surplus kromatik $s(H)$. Graf $G$ yang memiliki $n$ titik disebut elok terhadap $H, H$-elok, jika $R(G, H)=(n-1)(\chi(H)-1)+s(H)$. Notasi $t K_{m}$ merepresentasikan $t$ rangkap graf lengkap identik dengan $m$ titik, $K_{m}$. Dalam makalah ini dapat ditunjukkan bahwa graf lintasan $P_{n}$ adalah $t K_{m}$-elok untuk semua $m, t \geq 2$ dan $n$ cukup besar. Menggunakan sifat elok tersebut hasil lebih jauh juga diperoleh, yaitu bilangan Ramsey $R\left(G, t K_{m}\right)$ dapat ditentukan jika $G$ adalah gabungan graf lintasan sebarang.
\end{abstract}

Kata kunci: $(G, H)$-kritis, $H$-elok, graf lengkap, lintasan, bilangan Ramsey.

\section{INTRODUCTION}

All graphs in this paper are finite, undirected and simple. Let $G$ and $H$ be two graphs, where $H$ is a subgraph of $G$, we define $G-H$ as a graph obtained from $G$ by deleting the vertices of $H$ and all edges incident to them. Let $t$ be a

2000 Mathematics Subject Classification: 93C41

Received: 29-02-2012, revised: 30-01-2014, accepted: 30-01-2014. 
natural number and $G_{i}$ be a connected graph with the vertex set $V_{i}$ and the edge set $E_{i}$ for every $i=1,2, \ldots, t$. The disjoint union of graphs, $\bigcup_{i=1}^{t} G_{i}$, has the vertex set $\bigcup_{i=1}^{t} V_{i}$ and the edge set $\bigcup_{i=1}^{t} E_{i}$. Furthermore, if each $G_{i}$ is isomorphic to a connected graph $G$ then we denote by $t G$ the disjoint union of $t$ copies of $G$.

For graphs $G$ and $H$, the Ramsey number $R(G, H)$ is the minimum $n$ such that in every coloring of the edges of the complete graph $K_{n}$ with two colors, say red and blue, there is a red copy of $G$ or a blue copy of $H$. A graph $F$ is called $(G, H)$-free if $F$ contains no subgraph isomorphic to $G$ and its complement $\bar{F}$ contains no subgraph isomorphic to $H$. The Ramsey number $R(G, H)$ can be equivalently defined as the smallest natural number $n$ such that no $(G, H)$-free graph on $n$ vertices exists.

Determining $R(G, H)$ is a notoriously hard problem. Burr [4] showed that the problem of determining whether $R(G, H) \leq n$ for a given $n$ is NP-hard. Furthermore in Shaeffer [8] one can find a rare natural example of a problem higher than NP-hard in the polynomial hierarchy of computational complexity theory, that is, Ramsey arrowing is $\prod_{2}^{p}$-complete. The few known values of $R(G, H)$ are collected in the dynamic survey of Radziszowski [7].

Burr [3] proved the general lower bound

$$
R(G, H) \geq(n-1)(\chi(H)-1)+s(H),
$$

where $G$ is a connected graph of order $n, \chi(H)$ denotes the chromatic number of $H$ and $s(H)$ is its chromatic surplus, namely, the minimum cardinality of a color class taken over all proper colorings of $H$ with $\chi(H)$ colors. Motivated by this inequality, the graph $G$ is said to be $H$-good if equality holds in (1). Chvátal [5] proved that trees are $K_{m}$-good graphs. Sudarsana et al. [10] showed that path is a good graph with respect to $2 K_{m}$, and $P_{n}$ is also $t W_{4}$-good in [12]. Other result concerning the goodness of graphs with the chromatic surplus one can be found in Lin et al. [6]. However, the goodness of path $P_{n}$ with respect to $t K_{m}$ for $t \geq 2$ is still open. In this paper, we establish that $P_{n}$ is $t K_{m}$-good for $t \geq 2$ and sufficiently large $n$.

\section{KnOwn Results}

For the proof of our new result, Theorem 3.1, we use the following results.

Theorem 2.1 (Chvátal [5]). Let $n, m \geq 2$ be integers and $T_{n}$ is a tree of order $n$. Then, $R\left(T_{n}, K_{m}\right)=(n-1)(m-1)+1$.

Note that the chromatic surplus of $K_{m}, s\left(K_{m}\right)$, is equal to one and path $P_{n}$ is a tree of order $n$. Therefore, $R\left(P_{n}, K_{m}\right)=(n-1)(m-1)+1$.

Theorem 2.2 (Sudarsana et al. [10]). Let $m \geq 2$ and $n \geq 3$ be integers. Then, $R\left(P_{n}, 2 K_{m}\right)=(n-1)(m-1)+2$.

Lemma 2.3 (Sudarsana et al. [10]). Let $n$ and $t$ be positive integers. Then,

$$
R\left(P_{n}, t K_{2}\right)= \begin{cases}n+t-1, & t \leq\left\lfloor\frac{n}{2}\right\rfloor ; \\ 2 t+\left\lceil\frac{n}{2}\right\rceil-1, & t>\left\lfloor\frac{n}{2}\right\rfloor .\end{cases}
$$




\section{The Main Result}

The following theorem deals with the goodness of path $P_{n}$ with respect to $t$ identical copies of complete graphs, $t K_{m}$.

Theorem 3.1. Let $m, t \geq 2$ be integers and $g(t, m)=(t-2)((t m-2)(m-1)+1)+3$. If $n \geq g(t, m)$ then $R\left(P_{n}, t K_{m}\right)=(n-1)(m-1)+t$.

Proof of Theorem 3.1: The lower bound $R\left(P_{n}, t K_{m}\right) \geq(n-1)(m-1)+t$ follows from the fact that $(m-1) K_{n-1} \cup K_{t-1}$ is a $\left(P_{n}, t K_{m}\right)$-free graph of order $(n-1)(m-1)+t-1$.

To prove the upper bound $R\left(C_{n}, t K_{m}\right) \leq(n-1)(m-1)+t$ we use inductions on $t$ and $m$. For $t=2$, we have $g(2, m)=3$ and therefore Theorem 2.2 implies that $R\left(P_{n}, 2 K_{m}\right)=(n-1)(m-1)+2$ for $n \geq g(2, m)=3$. Hence, the assertion holds for $n \geq g(2, m)=3$. Assume that the theorem is true for $n \geq g(t-1, m)$, that is $R\left(P_{n},(t-1) K_{m}\right) \leq(n-1)(m-1)+t-1$.

From Lemma 2.3, we have $R\left(P_{n}, t K_{2}\right)=n+t-1$ for $n \geq 2 t$. Note that if $t \geq 2$ then $n \geq g(t, 2)>2 t$. Therefore, the theorem holds for $m=2$. Assume that $m \geq 3$ and the theorem is true for $n \geq g(t, m-1)$, that is $R\left(P_{n}, t K_{m-1}\right) \leq(n-1)(m-2)+t$.

Now we will show that the theorem is also valid for $n \geq g(t, m)$. Let $F$ be an arbitrary graph on $(n-1)(m-1)+t$ vertices. We shall show that $F$ contains $P_{n}$ or $\bar{F}$ contains $t K_{m}$. Note that Theorem 2.1 guarantees that $F$ contains $P_{n}$ or $\bar{F}$ contains $K_{m}$. If $F$ contains $P_{n}$ then we are done. Thus we may assume that $\bar{F}$ contains $K_{m}$. Since the subgraph $F-\bar{K}_{m}$ of $F$ has $(n-2)(m-1)+t-1$ vertices and $n-1 \geq g(t, m)-1>g(t-1, m)$, by the induction hypothesis on $t$ we know that $F-\bar{K}_{m}$ contains $P_{n-1}$ or the complement of $F-\bar{K}_{m}$ contains $(t-1) K_{m}$. If the complement of $F-\bar{K}_{m}$ contains $(t-1) K_{m}$ then by companying with the first ones we have a $t K_{m}$ in $\bar{F}$ and hence the proof is done. Thus, $F$ has a path $P_{n-1}$. Therefore, the subgraph $F-P_{n-1}$ of $F$ has $(n-1)(m-2)+t$ vertices. Note that $n \geq g(t, m)>g(t, m-1)$. By the induction hypothesis on $m$, we know that $F-P_{n-1}$ contains $P_{n}$ or the complement of $F-P_{n-1}$ contains $t K_{m-1}$. If $F-P_{n-1}$ contains $P_{n}$ then we are done. Hence we may assume that $F$ contains a path $P_{n-1}$ with vertex set, say $p_{1}, p_{2}, \ldots, p_{n-1}$ and edges $p_{i} p_{i+1}$ (subscripts modulo $(n-1)$ ), and that $\bar{F}$ contains $t$ disjoint copies $K_{m-1}^{1}, K_{m-1}^{2}, \ldots, K_{m-1}^{t}$ of the complete graph with $m-1$ vertices. It is clear that the subgraphs $P_{n-1}$ and $t K_{m-1}$ have no vertices in common.

Assume that $F$ contains no $P_{n}$. We will show that $\bar{F}$ contains $t K_{m}$. Thus, the end vertices $p_{1}$ and $p_{n-1}$ of path $P_{n-1}$ must not be adjacent to any vertices in $K_{m-1}^{1}, K_{m-1}^{2}, \ldots, K_{m-1}^{t}$. Therefore, the set $D=\left\{\left\{p_{1}\right\} \cup V\left(K_{m-1}^{1}\right)\right\} \cup\left\{\left\{p_{n-1}\right\} \cup\right.$ $\left.V\left(K_{m-1}^{2}\right)\right\}$ forms a $2 K_{m}$ in $\bar{F}$. Let us now consider the relation between the vertices in $A^{\prime}=\left\{p_{2}, p_{3}, \ldots, p_{n-2}\right\}$ and in $B^{\prime}=V\left(K_{m-1}^{3}\right) \cup V\left(K_{m-1}^{4}\right) \cup \ldots \cup V\left(K_{m-1}^{t}\right)$.

Since there is no $P_{n}$ in $F$, it follows that every two consecutive vertices $p_{i}, p_{i+1}$ in $A^{\prime}$ can not be adjacent to any vertices in $B^{\prime}$ for every $i \in\{2,3, \ldots, n-2\}$. Suppose that the neighborhood $N_{A^{\prime}}(u)$ in $A^{\prime}$ of a vertex $u \in B^{\prime}$ satisfies $\left|N_{A^{\prime}}(u) \cap V\left(P_{n-1}\right)\right| \geq$ $t m-1$. Let $p_{i}, p_{j} \in N_{A^{\prime}}(u) \cap V\left(P_{n-1}\right)$ with $i<j$. Note that $j-i>1$ since otherwise 
we can extend $P_{n-1}$ to a path of order $n$ containing $u$. If $p_{i+1} p_{j+1}$ is an edge in $F$ then we also have a new path $\left\{p_{1} p_{2} \ldots p_{i} u p_{j} p_{j-1} p_{j-2} \ldots p_{i+1} p_{j+1} p_{j+2} \ldots p_{n-1}\right\}$ of length $n-1$ in $F$. If $p_{i+1} p_{j+1}$ is not an edge for every pair $p_{i}, p_{j} \in N_{A^{\prime}}(u) \cap$ $V\left(P_{n-1}\right)$ then $\left\{p_{i+1}: p_{i} \in N_{A^{\prime}}(u) \cap V\left(P_{n-1}\right)\right\} \cup\{u\}$ is a set of $t m$ independent vertices in $F$ and we obtain that $\bar{F}$ contains $t K_{m}$. Hence, for each $u \in B^{\prime}$ we have $\left|N_{A^{\prime}}(u) \cap V\left(P_{n-1}\right)\right| \leq t m-2$. Therefore,

$$
\left|A \backslash \bigcup_{u \in B^{\prime}} N_{A^{\prime}}(u)\right| \geq n-3-(t-2)(t m-2)(m-1) .
$$

Since $n \geq g(t, m)$, it follows that there are at least $t-2$ vertices in $A^{\prime}$ which are adjacent to no vertex in $B^{\prime}$ and hence together with $D$ we have that $\bar{F}$ contains $t K_{m}$. This concludes the proof of Theorem 3.1.

By extending previous results of Baskoro et al. [1] and Stahl [9], Bielak [2] and Sudarsana et al. [11] independently proved a formula for $R(G, H)$ when every connected component of $G$ is an $H$-good graph. This result motivates the study of general families of $H$-good graphs. In particular, Theorem 3.1 provides the following computation of $R\left(G, t K_{m}\right)$, if $G$ is a set of disjoint paths (linear forest).

Corollary 3.2. Let $m, t \geq 2$ be integers and $g(t, m)=(t-2)((t m-2)(m-1)+1)+3$. Let $G \simeq \bigcup_{i=1}^{k} l_{i} P_{n_{i}}$, where $l_{i} \geq 1$ and each $P_{n_{i}}$ is a path of order $n_{i}$.

If $n_{1} \geq n_{2} \geq \ldots \geq n_{k} \geq g(t, m)$ then

$$
R\left(G, t K_{m}\right)=\max _{1 \leq i \leq k}\left\{\left(n_{i}-1\right)(m-2)+\sum_{j=1}^{i} l_{j} n_{j}\right\}+t-1 .
$$

Acknowledgements. The author is thankful to the anonymous referees for some comments that helped to improve the presentation of the manuscript. The author also gratefully acknowledges Professor Oriol Serra for helpful discussion while doing this research. This research was supported by Directorate General of Higher Education (DGHE), Indonesian State Ministry of Education and Culture under Fundamental research grant: 125.C/un 28.2/PL/2012.

\section{REFERENCES}

[1] Baskoro, E.T., Hasmawati, and Assiyatun, H., "Note. The Ramsey number for disjoint unions of trees", Discrete Math. 306 (2006), 3297-3301.

[2] Bielak, H., "Ramsey numbers for a disjoint union of good graphs", Discrete Math. 310 (2010), 1501-1505.

[3] Burr S.A., "Ramsey numbers involving long suspended paths", J. London Math. Soc. 24:2 (1981), 405-413.

[4] Burr, S.A., "Determining generalized Ramsey numbers is NP-hard", Ars Combin. 17 (1984), 21-25.

[5] Chvátal, V., "Tree-complete graph Ramsey number", J. Graph Theory 1 (1977), 93. 
[6] Lin, Q., Li, Y., and Dong, L., "Ramsey goodness and generalized stars", Europ. J. Combin., 31 (2010), 1228-1234.

[7] Radziszowski, S.P., "Small Ramsey numbers", Electron. J. Combin. (2009), DS1.12, < http://www.combinatorics.org $\rangle$.

[8] Schaefer, M., "Graph Ramsey theory and the polynomial hierarchy", J. Comput. Sys. Sci. 62 (2001), 290-322.

[9] Stahl, S., "On the Ramsey number $r\left(F, K_{m}\right)$ where $F$ is a forest", Canadian J. Math. 27 (1975), 585-589.

[10] Sudarsana, I W., Assiyatun, H., Adiwijaya, and Musdalifah, S., "The Ramsey number for a linear forest versus two identical copies of complete graphs", Discrete Math. Algo. Appl. 2 (2010), 437-444.

[11] Sudarsana, I W., Baskoro, E.T., Assiyatun, H., and Uttunggadewa, S., "The Ramsey numbers for the union graph with $H$-good components", Far East J. Math. Sci. 39:1 (2010), 29-40.

[12] Sudarsana, I W., "The Goodness of long path with respect to multiple copies of small wheel", Far East J. Math. Sci. 59:1 (2011), 47-54. 